\title{
INFORME SOBRE PROYECTO DE LEY QUE SANCIONA CON CÁRCEL A QUIENES NIEGUEN, JUSTIFIQUEN O MINIMICEN LOS DELITOS DE LESA HUMANIDAD COMETIDOS EN CHILE. BOLETÍN No 8049-17
}

Con fecha 12 de abril de 2012, la Comisión de Derechos Humanos de la H. Cámara de Diputados ha tenido a bien solicitar al Centro de Estudios Constitucionales de Chile, de la Universidad de Talca, la emisión de un informe desde la perspectiva constitucional con nuestra opinión respecto del proyecto de ley que sanciona con cárcel a quienes nieguen, justifiquen o minimicen los delitos de lesa humanidad cometidos en Chile entre 1973 y 1990.

En cumplimiento de este encargo, venimos en emitir el siguiente informe para ser compartido con los honorables miembros de la Comisión.

\section{INTRODUCCIÓN}

Este informe se estructura en cuatro apartados. El primero dedicado a analizar los criterios del derecho comparado en relación a la constitucionalidad de las normas penales que sancionan la negación, justificación de los crímenes de lesa humanidad y el holocausto; la segunda a analizar aspectos de derecho constitucional chileno sobre la materia; el tercero a analizar el derecho a la libertad de opinión e información y sus límites; el cuarto a desarrollar consideraciones sobre las limitaciones legítimas que pueden imponerse a la libertad de opinión, información

y expresión y una conclusión final sobre el análisis concreto de la norma que se propone en el Boletín 8049.

\section{Aspectos generales de Derecho comparado SOBRE LA TIPIFICACIÓN PROPUESTA}

Los antecedentes comparados del proyecto que se analiza se encuentran en los hechos ocurridos en Europa luego de la II Guerra Mundial. Una vez que la comunidad internacional tomó conciencia de los graves y repudiables crímenes ocurridos durante el III Reich y sus responsables fueron sometidos a proceso $\mathrm{y}$ condenados, paulatinamente fue tomando forma una corriente que aunque marginal, negaba la política de exterminio nazi contra los judíos. Es lo que se ha denominado negacionismo o revisionismo histórico, es decir, un discurso que 
cuestiona o niega la realidad del exterminio judío por los nazis, que lo justifica o lo relativiza, y que en definitiva pretende instalar un margen de duda sobre este genocidio o bien que busca borrarlo de la historia.

El revisionismo histórico provocó reacciones que trasladaron el debate sobre los límites a la libertad de expresión y la comisión de delitos a partir de su quebrantamiento, ante el sistema europeo de protección a los derechos humanos y, también, fue la razón para el desarrollo de tipos penales que calificaron como delito la negación o justificación del holocausto.

Asimismo, entre otros países, Alemania incorporó en su Constitución cláusulas de protección de la democracia:

Artículo 21. Partidos políticos:

(1) Los partidos participan en la formación de la voluntad politica del pueblo. Su fundación es libre. Su organización interna debe responder a los principios democráticos. Los partidos deberán dar cuenta públicamente de la procedencia y uso de sus recursos, asi como de su patrimonio.

(2) Los partidos que por sus fines o por el comportamiento de sus adherentes tiendan a desvirtuar o eliminar el régimen fundamental de libertad y democracia, o a poner en peligro la existencia de la República Federal de Alemania, son inconstitucionales. Sobre la constitucionalidad decidirá la Corte Constitucional Federal.

(3) La regulación se hará por leyes federales.

La Constitución alemana sitúa en el centro de su catálogo de derechos la protección de la dignidad humana; y en cuanto a la libertad de opinión, señala:

Artículo 50: Libertad de opinión, de medios de comunicación, artística y científica

(1) Toda persona tiene el derecho a expresar y difundir libremente su opinión oralmente, por escrito y a través de la imagen, y de informarse sin trabas en fuentes accesibles a todos. La libertad de prensa y la libertad de información por radio, televisión y cinematografía serán garantizadas. La censura está prohibida.

(2) Estos derechos tienen sus límites en las disposiciones de las leyes generales, en las disposiciones legales adoptadas para la protección de la juventud y en el derecho al honor personal.

Cómo en la Constitución chilena (art.1), en la Constitución alemana la dignidad de la persona juega un rol esencial y como base del sistema de derechos que la Constitución ampara. Se trata de un "valor supremo del ordenamiento jurídico y un reducto intangible" que se protege siempre y contra toda agresión. El papel central de la dignidad humana se relacional en el caso alemán con el contexto histórico en el que se elaboró la Constitución y en la necesidad de instalar a nivel constitucional el mayor y mejor nivel de protección de la persona, precisamente como una reacción a los graves acontecimientos y a los crímenes cometidos contra 
el pueblo judío por el III Reich. Fue en la propia Constitución donde se reflejó la traumática experiencia de la II Guerra Mundial, estas razones son las que impulsaron la consagración de la democracia militante, contenida en los artículos 9 inciso 2; 18 y 21. Es precisamente en este contexto que, además, a nivel legal se reprime penalmente la negación del holocausto, que hasta la reforma de 1994 fue perseguida como injuria (art. 185 del Código Penal); como difamación a la memoria de un difunto (artículo 189) o como delito de incitación al odio (artículo 130). A partir de 1994, la Ley de Lucha contra la Criminalidad, agregó al art. 130 que "la negación, aprobación o minimización en público o en el curso de una reunión, de una manera de ser susceptible de alterar la paz pública, del genocidio perpetrado bajo el régimen nacional-socialista, será castigada con una pena de hasta cinco años o multa”. Sobre esta tipificación, afirma Juan María Bilbao, que ella responde "más a razones político-simbólicas que a una ampliación del ámbito punible respecto a una situación anterior puesto que ya existía una jurisprudencia consolidada" sobre la materia.

Las normas antes mencionadas han dado origen a una jurisprudencia del Tribunal Europeo de Derechos Humanos que es relevante a la hora de examinar el proyecto que aquí se analiza, dado que introduce algunas prevenciones que consideramos importantes a la hora de abordar su estudio de Constitucionalidad. Dicho lo anterior, se debe prevenir que las observaciones que se plantean no se relacionan con la iniciativa que sanciona la negación o justificación de las graves violaciones a los derechos humanos cometidas durante la dictadura, sino que con la tipificación que esta moción propone tal y como se desprenderá de los siguientes apartados.

En cuanto a los criterios de la Comisión Europea de Derechos Humanos, ésta ha señalado que existen injerencias y límites a la libertad de expresión cuando se trata de, por ejemplo, la difusión de folletos que desconocen o cuestionan el número de víctimas del holocausto aunque no se haga referencia a una persona en concreto sino que se refiera en general al pueblo judío. En efecto se dice que es suficiente con un cuestionamiento a los crímenes cometidos contra pueblo judío para que éste se entienda afectado en su totalidad y por cada uno de sus integrantes.

En otro caso conocido por la Comisión de septiembre de 1995: Caso Otto E.F.A. Remer contra Alemania, ésta declaró inadmisible una demanda presen-

${ }^{1}$ BilbaO, Juan María: "La negación del holocausto en la jurisprudencia del Tribunal Europeo de Derechos Humanos: la endeble justificación de los tipos penales contrarios a la libertad de expresión". Estudios en Homenaje a Héctor Fix-Zamudio. Biblioteca jurídica virtual del Instituto de Investigaciones Jurídicas de la UMAM 1997, pp. 714. 
tada en 1994 por un general nazi en retiro, conocido negacionista, que en una publicación (5 números de una revista entre 1991 y 1992, en total ochenta mil ejemplares) negaba la existencia de cámaras de gas durante el régimen nazi. La comisión consideró que el art. 130 y otras normas que penalizan el negacionismo son normas que protegen la armonía y la paz social y consideró procedentes los límites a la libertad de opinión e información, además por tratarse de una interferencia prevista en la ley.

Los criterios, primero de la Comisión y luego del Tribunal Europeo de Derechos Humanos en relación a los límites a la libertad de expresión y la configuración de tipos penales por la negación o apología del holocausto, han sido invariables y se han dirigido en tres direcciones.

Por una parte, se han referido a la aplicación de tipos penales contenidos en el ordenamiento alemán (a partir de la norma a la que ya se ha hecho referencia; austriaco (por la Ley de Prohibición del Nacional- Socialismo); y francés (por aplicación de la Ley Gayssot 90-615 de 1990 que castiga actos racistas, antisemitas y xenófobos y la apología de los crímenes contra la humanidad) considerando que la condena por vulneración de dichas normas no vulneraba el Convenio Europeo de Derechos Humanos dado que:

a) si bien se produjo una injerencia en la libertad de expresión del demandante, la restricción estaba prevista en la ley.

b) la medida no resultaba ni arbitraria ni irrazonable y responde a una finalidad legítima reconocida por el Convenio en el art. 10.2, tal es la preservación del orden público, la prevención del delito y la protección de la reputación de los demás.

c) se trata de una medida necesaria en una sociedad democrática, especialmente cuando se trata de salvaguardar los derechos de grupos que históricamente han sufrido discriminación.

De tal manera que en el ámbito europeo se ha considerado admisible el desarrollo normativo de tipos penales que castigan la negación, apología, y la banalización del holocausto y también, en el caso francés, de los crímenes de lesa humanidad tal y como han sido definidos en el art. 6 del Estatuto Militar internacional anexo al Acuerdo de Londres del 8 de agosto de 1945. Asimismo, si bien se ha reconocido que se trata de injerencias en la libertad de expresión, esta limitación ha sido considerada admisible por estar comprendida en la ley, por tener una finalidad legítima y por ser necesaria en una sociedad democrática ${ }^{2}$.

\footnotetext{
${ }^{2}$ Entre otras vid: Comisión Europea: caso Otto E.F.A. Remer contra Alemania de 6 de septiembre de 1995; asunto Herwig Nachtmann contra Austria de 9 de septiembre de 1998; asunto H.J. Schimanek contra Austria de 1 de febrero de 2000; Tribunal Europeo de Derechos Humanos asunto Garaudy contra Francia de 24 de junio de 2003.
} 


\section{Aspectos De Derecho CONSTITUCIONAL CHILENO.}

En nuestra Constitución Política de la República se asegura la dignidad de la persona humana y los derechos fundamentales cuyos atributos y garantías están contenidos tanto en el propio texto de la Carta Fundamental en su artículo 19, como asimismo, por derechos implícitos que emanan de los principios constitucionales constituyendo normas adscritas al texto constitucional, como también por los atributos y garantías de los derechos fundamentales asegurados por normas del derecho convencional internacional ratificadas por Chile y que se encuentren vigentes, en virtud de la norma de reenvío prevista en el artículo $5^{\circ}$ inciso segundo de la Constitución, por lo que puede sostenerse la existencia de un verdadero bloque de constitucionalidad de los derechos fundamentales.

Por otra parte, en atención a este bloque constitucional de derechos debemos entender incorporados los atributos y garantías contenidos en la Convención Americana de Derechos Humanos, en su artículo 13, como asimismo, los contenidos en el artículo del Pacto Internacional de Derechos Civiles y Políticos de Naciones Unidas referentes a la libertad de expresión, que en nuestro texto constitucional está contenido en el artículo 19 No 12, como libertad de opinión e información.

Es necesario tener presente el reconocimiento de jurisdicción hecha a la Corte Interamericana sobre Derechos Humanos, la cual ha determinado desde el fallo Almonacid vs. Chile, la obligación de los Estados Partes a través de sus órganos estatales legislativos, administrativos y jurisdiccionales de realizar un control de convencionalidad que exige no sólo respetar y garantizar el corpus iuris interamericano, sino también el estándar mínimo fijado por las sentencias contenciosas y las opiniones consultivas de la Corte Interamericana.

A su vez, el marco normativo compartido por nuestra Constitución y el sistema internacional de derechos humanos del que formamos parte establece un conjunto de garantías normativas respecto de la limitación o restricción de derechos fundamentales, como es en el caso analizado, el de libertad de opinión e información.

Dichas garantías normativas están dadas por el respeto al contenido esencial de cada derecho fundamental, la garantía que los derechos fundamentales sólo pueden ser objeto de limitaciones o restricciones en virtud del principio de reserva legal, como asimismo que dichas limitaciones deben tener por objeto asegurar un bien jurídico constitucional explícito o implícito, como asimismo, justificarse en virtud del principio de proporcionalidad, lo que exige que la medida legislativa adoptada sea adecuada al fin constitucional que la fundamenta; el que la medida legislativa sea estrictamente necesaria, no habiendo otra que alcanzando la finalidad, afecte en menor grado el derecho que se limita; como asimismo evaluar que el daño 
producido por la afectación del derecho se vea compensada por una mayor ventaja para el bien común de la sociedad.

Así, sólo la Constitución y la ley pueden ser consideradas fuentes de limitación de los derechos fundamentales, ya que su carácter de derechos fundamentales deriva de su aseguramiento constitucional expreso o implícito, como asimismo, por el hecho de que su regulación está reservada exclusivamente al legislador (Artículos 19 No 26, 32 No 6; 63 y 64 de la Constitución). Ninguna norma constitucional habilita a ningún otro órgano o autoridad para introducir válidamente limitacionesrestricciones de los derechos fundamentales.

El legislador puede configurar y regular los derechos en los casos que autoriza la Carta Fundamental, teniendo siempre como límite la Constitución, ya que cada derecho está llamado a ejercerse, libremente, en su ámbito propio, en armonía con todos los demás derechos y bienes constitucionales.

\section{La reserva de ley para la restricción o limitación de derechos}

La reserva de la ley asegura que la elaboración, debate y aprobación de ciertas materias se produzca mediante el procedimiento legislativo parlamentario. Se trata que sea el Congreso Nacional el que regule las materias que el constituyente le ha dado mayor trascendencia e importancia, sometiéndolos al procedimiento legislativo, que se basa en los principios de publicidad, contradicción y debate, reforzándose respecto de esas materias la garantía del pluralismo político. Además, en una perspectiva en que todos los sectores políticos representativos del país son escuchados, se puede lograr un mejor orden de prelación material y temporal, una mayor justificación racional y una definición pública más transparente del bien común.

En el ordenamiento constitucional chileno, dos preceptos que fundamentan el principio de reserva de ley para la regulación del ejercicio de los derechos, el artículo 63 No 20, el que sostiene que son materia de ley toda norma de carácter general y obligatoria que estatuya las bases esenciales de un ordenamiento jurídico, como asimismo, el artículo 19 No 26, que determina la "seguridad de que los preceptos legales que por mandato de la Constitución regulan o complementan las garantías que ésta establece o que las limiten en los casos en que ella lo autoriza, no podrán afectar los derechos en su esencia, ni imponer condiciones, tributos o requisitos que impidan su libre ejercicio".

El principio de reserva de ley se refuerza en el caso en que el Constituyente reserva la regulación de la materia al legislador de quórum especial (ley orgánica constitucional o ley de quórum calificado), en cuyo caso se requiere de mayorías calificadas (4/7 o mayoría absoluta, según el caso), y, por tanto, de mayor acuerdo parlamentario. En todo caso, no hay un criterio uniforme para determinar qué materias corresponden 
a qué tipo de legislador, ya que en materia de derechos, éstos pueden ser regulados, en general, por el legislador ordinario y en casos especiales, algunas materias se dejan al legislador orgánico y otras al legislador de quórum calificado. Por otra parte, en la mayoría de los órganos constitucionales, el desarrollo de su organización y atribuciones queda entregado al legislador orgánico constitucional, mientras otras regulaciones institucionales se dejan al legislador de quórum calificado.

El Tribunal Constitucional señala que "es principio general y básico del Derecho Constitucional chileno la "reserva legal" en la regulación del ejercicio de los derechos fundamentales, esto es, toca al legislador, y sólo a él, disponer normas al respecto, sin más excepción que la referente al derecho de reunión en lugares de uso público, regido su ejercicio por disposiciones generales de policía (artículo 19 No 13 de la Constitución), pero tanto aquellas regulaciones como ésta no puede jamás afectar el contenido esencial de tales derechos (artículo 19, No 26, de la Carta Fundamental)"3.

En la materia, el Tribunal Constitucional ha establecido que regular o limitar legalmente los derechos, jamás deberá interpretarse en el sentido que impida el libre ejercicio de ellos. Por otra parte, si bien al regular se pueden establecer limitaciones y restricciones al ejercicio de un derecho, claramente, de acuerdo al texto de la Constitución, deben ordenarse por ley y no mediante normas de carácter administrativo", el considerando $13^{\circ}$ agrega "Que, no está demás recordar que conforme con lo que dispone imperativamente la Constitución, los órganos del Estado están al servicio de las personas y al cumplir su finalidad de bien común deben hacerlo con "pleno respeto" de sus derechos y garantías (artículo $1^{\circ}$, inciso $4^{\circ}$ ), debiendo incluso promover su ejercicio, esto es, sin vulneración, perturbación o privación de ellos, y se atenta en su contra cuando se infringe una garantía tan básica como es la 'reserva legal' dispuesta por la Constitución para la regulación de la materia" ${ }^{4}$.

En la medida que la reserva de ley es reserva de actuación del Congreso Nacional con el procedimiento establecido en los artículos 65 a 75 de la Constitución, éste debe adoptar en todos los ámbitos básicos y, en especial, en el de los derechos constitucionales, las decisiones básicas, esenciales o importantes, lo que, a su vez, permite al Poder Ejecutivo la adopción de las decisiones que no sean básicas o esenciales, mediante reglamento.

En esta materia, el Tribunal Constitucional chileno ha señalado que

"es principio general y básico del Derecho Constitucional chileno la reserva legal en la regulación del ejercicio de los derechos fundamentales; esto es, toca al legislador,

${ }^{3}$ Sentencia del Tribunal Constitucional, Rol № 239, de 16 de julio de 1996, considerando $9^{\circ}$.

${ }^{4}$ Sentencia del Tribunal Constitucional de fecha 6 de abril de 1993, considerandos $12^{\circ}$ y $13^{\circ}$. 
y sólo a él, disponer normas al respecto, sin más excepción que la referente al derecho de reunión en lugares de uso público, regido su ejercicio por disposiciones generales de policía (articulo $19 N^{\circ} 13$, de la Constitución), pero tanto aquellas regulaciones como ésta no pueden afectar el contenido esencial de tales derechos".

En el caso de reserva legal en el nivel más absoluto, la Constitución exige

"un mayor grado de rigurosidad en la amplitud de la temática regulada, minuciosidad de la normativa que dicta, profundidad o grado de elaboración de los textos preceptivos que aprueba, pronunciamiento sobre conceptos, requisitos, procedimientos $y$ control de las regulaciones acordadas y otras cualidades que obligan a reconocer que, el ámbito de la potestad reglamentaria de ejecución, se halla más restringido o subordinado". 6

A su vez, el Tribunal Constitucional ha precisado estos criterios, señalando

"No puede la ley, por ende, reputarse tal en su forma y sustancia si el legislador ha creido haber realizado su función con meros enunciados globales, plasmados en cláusulas abiertas, o a través de fórmulas que se remiten, en blanco, a la potestad reglamentaria, sea aduciendo o no que se trata de asuntos mutables, complejos o circunstanciales. Obrar asi implica, en realidad, ampliar el margen limitado que cabe reconocer a la discrecionalidad administrativa, con detrimento ostensible de la seguridad juridica". ${ }^{7}$

El Tribunal Constitucional ha precisado estos criterios, señalando

"No puede la ley, por ende, reputarse tal en su forma y sustancia si el legislador ha creido haber realizado su función con meros enunciados globales, plasmados en cláusulas abiertas, o a través de fórmulas que se remiten, en blanco, a la potestad reglamentaria, sea aduciendo o no que se trata de asuntos mutables, complejos o circunstanciales. Obrar así implica, en realidad, ampliar el margen limitado que cabe reconocer a la discrecionalidad administrativa, con detrimento ostensible de la seguridad jurídica".

El Tribunal Constitucional ha precisado, en diversas sentencias, que las disposiciones legales que regulen el ejercicio de los derechos, deben reunir los requisitos de determinación y especificidad. El requisito de determinación "exige que los derechos que puedan ser afectados se señalen, en forma concreta en la norma legal" y el requisito de especificidad requiere que la norma legal "indique de manera precisa, las medidas especiales que se pueden adoptar con tal finalidad. Por último, los derechos

\footnotetext{
${ }^{5}$ Sentencia del Tribunal Constitucional, Rol No 239, de 16 de julio de 1996, considerando 9.

${ }^{6}$ Sentencia Tribunal Constitucional, Rol No 370, del 9 de abril de 2003, considerando $18^{\circ}$.

${ }^{7}$ Sentencia Tribunal Constitucional, Rol No 370, del 9 de abril de 2003, considerando $19^{\circ}$.

${ }^{8}$ Sentencia Tribunal Constitucional, Rol No 370, del 9 de abril de 2003, considerando decimonoveno.
} 
no pueden ser afectados en su esencia, ni imponerles condiciones, tributos o requisitos que impidan su libre ejercicio".?

En esta materia, se ha desarrollado en la jurisprudencia comparada el principio de la "taxatividad progresiva" fundamental. En cuanto más intensa sea la regulación de un derecho fundamental, más taxativa debe ser la norma que la prevé. Sobre la materia debemos señalar que la densidad con que el legislador debe regular los derechos fundamentales es variable, ella debe ser especialmente intensa en aquellos casos que se establezcan tipos penales o conductas antijurídicas, pudiendo ser menos intensa cuando simplemente se regula un derecho fundamental.

La reserva de ley como reserva de regulación del Congreso y de regulación legal más absoluta o más relativa, se transforma en último caso, en reserva de sentencia, ya que será el Tribunal Constitucional el que determinará dicho criterio en cada hipótesis normativa, el cual en virtud del principio de prohibición de exceso, propio del estado de derecho, deberá ponderar la intervención del legislador en el ámbito de protección de los derechos esenciales fundamentales, la cual debe ser adecuada, necesaria y proporcionada.

Es necesario considerar también la doctrina emanada de los tribunales internacionales de derechos humanos, entre los cuales la Corte Europea de Derechos Humanos tiene una jurisprudencia más consolidada, que sostiene las exigencias de precisión y previsibilidad de los límites que imponen y el modo de aplicación de la regulación legal, en cuanto a las restricciones o limitaciones de los derechos fundamentales, cuya vulneración afecta el principio de seguridad jurídica entendido como certeza sobre el orden normativo aplicable y perspectiva razonablemente fundada de la persona sobre cual será la actuación de la autoridad, en aplicación del derecho vigente.

\section{El respeto al contenido esencial del derecho.}

En el caso chileno, la Constitución de 1980, en el artículo 19 asegura a todas las personas: No 26 "La seguridad de que los preceptos legales que por mandato de la Constitución regulen o complementen las garantías que esta establece o que las limiten en los casos en que ello lo autoriza, no podrán afectar los derechos en su esencia, ni imponer condiciones, tributos o requisitos que impidan su libre ejercicio". A ello debe unirse el artículo $5^{\circ}$ inciso $2^{\circ}$ de la Constitución que determina que "La soberanía tiene como

\footnotetext{
${ }^{9}$ Sentencia Tribunal Constitucional de Chile, Rol No 325, del 26 de junio de 2001, considerando 38, sobre restricción a la circulación de vehículos catalíticos.

${ }^{10}$ Brage Camazano, Joaquín. (2004). Los límites a los derechos fundamentales. Ed. Dykinson, Madrid, pp. 320 y ss.
} 
límite los derechos esenciales que emanan de la naturaleza humana”, con lo cual, el límite del contenido de los derechos se proyecta no sólo al legislador, sino también al poder constituyente instituido, estableciendo una prohibición de regresión o expresada de manera positiva, una garantía de irreversibilidad en materia de derechos fundamentales, lo que nos sitúa, en la materia, en una afirmación y garantía mayor de los derechos fundamentales que los tres países antes mencionados.

El objetivo del artículo 19 No 26 no es atribuir un poder al legislador, sino limitar el que tiene atribuido por la propia Constitución.

El legislador está obligado a respetar y tiene prohibido, constitucionalmente, afectar el contenido esencial de los derechos. Dicho contenido esencial se establece como la barrera constitucional insuperable e infranqueable en la tarea de establecer posibles limitaciones de los derechos, constituye un límite al poder de limitar los derechos, conformando la dimensión constitucional del derecho, proveniente de la tradición jurídica que se debe preservar.

$\mathrm{Al}$ respecto el Tribunal Constitucional chileno se ha pronunciado sobre el sentido y alcance del contenido esencial de los derechos, señalando:

"la esencia del derecho debemos conceptuarla desde el punto de vista del ordenamiento positivo y dentro de este ámbito precisar el alcance de la norma constitucional en los términos más sencillos, para que sea entendido por todos y no sólo por los estudiosos de la ciencia jurídica. Desde esta perspectiva, debemos entender que un derecho es afectado en su "esencia" cuando se la prive de aquello que le es consustancial, de manera tal que deja de ser reconocible y que se impide "el libre ejercicio" en aquellos casos en que el legislador lo somete a exigencias que lo hacen irrealizable, lo entraban más allá de lo razonable o lo privan de tutela jurídica. ${ }^{11}$

Así lo ha reiterado el Tribunal Constitucional en diversos fallos más recientes:

"38". Que esta Magistratura ha venido sosteniendo, consistentemente, que se afecta la esencia de un derecho cuando "se le priva de aquello que le es consustancial, de manera tal que deja de ser reconocible" (sentencia Rol $N^{o} 43$ ), cuando la respectiva limitación llegue a consistir en la "privación" del derecho (Rol No 226) y cuando se imponen tributos, requisitos o condiciones que hagan absolutamente ilusorio el ejercicio del mismo (Sentencia Rol No 280). Al mismo tiempo, ha entendido que se impide el libre ejercicio de un derecho en aquellos casos en que "el legislador lo somete a exigencias que lo hacen irrealizable, lo entraban más allá de lo razonable o lo privan de tutela jurídica" (Rol No 43, entre otros); ${ }^{12}$

\footnotetext{
${ }^{11}$ Sentencia del Tribunal Constitucional chileno, Rol No 43 de 24 de febrero de 1987, considerandos 20 y 21. En el mismo sentido Sentencia del Tribunal Constitucional, roles 200, 226 y 280.

${ }^{12}$ Sentencia del Tribunal Constitucional, Rol No 1.182-08-INA, de dieciocho de noviembre de dos mil ocho, considerando $38^{\circ}$.
} 
"36: Que esta Magistratura ha considerado que "un derecho es afectado en su 'esencia' cuando se le priva de aquello que le es consustancial, de manera tal que deja de ser reconocible (sentencia Rol $N^{o} 43$, de 24 de febrero de 1987, considerando

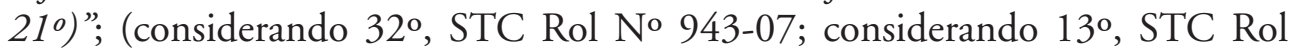
No 1185-08);"13

\section{EL DERECHO A LA LIBERTAD DE OPINIÓN E INFORMACIÓN Y SUS LÍMITES}

La norma constitucional sobre libertad de opinión e información, en la parte pertinente sostiene:

La Constitución chilena en el artículo 19 asegura a todas las personas, en numeral No 12:

"La libertad de emitir opinión y la de informar, sin censura previa, en cualquier forma y por cualquier medio, sin perjuicio de responder de los delitos y abusos que se cometen en el ejercicio de estas libertades, en conformidad a la ley, la que deberá ser de quórum calificado.

La ley en ningún caso podrá establecer monopolio estatal sobre los medios de comunicación social.

Toda persona natural o jurídica ofendida o injustamente aludida por algún medio de comunicación social, tiene derecho a que su declaración o rectificación sea gratuitamente difundida, en las condiciones que la ley determine, por el medio de comunicación social en que esa información hubiere sido emitida".

El Pacto Internacional de Derechos Civiles y Políticos de Naciones Unidas (P.I.D.C. y P.), en su artículo 19, determina:

"1. Nadie podrá ser molestado a causa de sus opiniones.

"2. Toda persona tiene derecho a la libertad de expresión; este derecho comprende la libertad de buscar, recibir y difundir informaciones e ideas de toda índole, sin consideración de fronteras, ya sea oralmente, por escrito o en forma impresa o artística, o por cualquier otro medio de su elección.

“3. El ejercicio del derecho previsto en el párrafo 2 de este artículo entraña deberes y responsabilidades especiales. Por consiguiente, puede estar sujeto a ciertas restricciones que deberían, sin embargo, estar expresamente fijadas por la ley y ser necesarias para:

a) asegurar el respeto a los derechos o a la reputación de los demás;

b) la protección de la seguridad nacional, el orden público o la salud o la moral públicas".

\footnotetext{
${ }^{13}$ Sentencia del Tribunal Constitucional, Rol No 1.463-09-INA. de veintitrés de septiembre de dos mil diez, considerando $36^{\circ}$.
} 
El artículo 20 del P.I.D.C. y P. agrega la siguiente normativa:

"1. Toda propaganda a favor de la guerra estará prohibida por la ley.

"2. Toda apología del odio nacional, racial o religioso que constituya incitación a la discriminación, la habilidad o la violencia estará prohibida por la ley".

A su vez, el artículo 13, la CADH, determina lo siguiente:

"1. Toda persona tiene derecho a la libertad de pensamiento y expresión. Este derecho comprende la libertad de buscar, recibir y difundir información e ideas de toda indole, sin consideración de fronteras, ya sea oralmente, por escrito o en forma impresa o artistica, o por cualquier otro procedimiento de su elección.

"2. El ejercicio del derecho previsto en el inciso precedente no puede estar sujeto a previa censura, sino a responsabilidades ulteriores, las que deben estar expresamente fijadas por la ley y ser necesario para asegurar:

a) el respeto a los derechos o a la reputación de los demás, o

b) la protección de la seguridad nacional, el orden público o la salud o la moral públicos.

“3. No se puede restringir el derecho de expresión por vias o medios indirectos, tales como el abuso de controles oficiales o particulares de papel para periódicos, de frecuencias radioeléctricas o de enseres o aparatos usados en la difusión de información, o por cualesquiera otros medios encaminados a impedir la comunicación y la circulación de ideas y opiniones.

"4. Los espectáculos públicos pueden ser sometidos por la ley a censura previa, con el exclusivo objeto de regular el acceso a ellos para la protección moral de la infancia $y$ la adolescencia, sin perjuicio de lo establecido en el inciso $2^{\circ}$.

"5. Estará prohibida por la ley toda propaganda a favor de la guerra y toda apología del odio nacional, racial o religioso que constituyan incitaciones a la violencia o cualquier otra acción similar contra cualquier persona o grupo de personas, por ningún motivo, inclusive los de raza, color, religión, idioma u origen nacional".

Este es el marco general jurídico en que debe ser examinada la moción legislativa sometida a nuestra consideración.

\section{CONSIDERACIONES SOBRE LAS LIMITACIONES A LA LIBERTAD DE OPINIÓN E INFORMACIÓN O A LA LIBERTAD DE EXPRESIÓN QUE PUEDEN LEGÍTIMAMENTE ESTABLECERSE EN NUESTRO ORDENAMIENTO JURÍDICO.}

Ningún derecho fundamental es absoluto, en el sentido de no admitir limitaciones, todos pueden ser objeto de limitaciones por medio del legislador, reuniendo los requisitos de determinación y especificidad, respetando el contenido esencial del derecho, y los postulados de razonabilidad y de proporcionalidad, en el marco de una sociedad democrática, donde se ejerce una amplia tolerancia. 
El bloque constitucional de la libertad de expresión en su dimensión de libertad de opinión es la facultad de que disponen las personas para expresar por cualquier medio y forma, sin censura, lo que creen, piensan, saben o sienten, a través de ideas y juicios de valor, los que son por su naturaleza, de carácter subjetivo, pudiendo además intercambiar dichas ideas y debatirlas con otras personas, teniendo como límite el no emitir expresiones vejatorias o insultantes, lo que normalmente se encuentra sancionado como ultima ratio por el Código Penal a través de los delitos de injuria y calumnia.

La libre expresión "no sólo ampara la exteriorización de dichos contenidos a través de proposiciones lingüísticas 'expresivas', sino también mediante proposiciones 'prescriptivas' dirigidas a influir en el comportamiento de otras personas, siempre y cuando esa influencia no se convierta en coacción". ${ }^{14}$

La información a diferencia de la opinión es la elaboración de un juicio de ser, de una situación o de un hecho comprobable.

La libertad de información incluye la libertad de recibir como la de comunicar, publicar y difundir informaciones (hechos o acontecimientos) $\mathrm{u}$ opiniones (juicios de valor o ideas sobre tales hechos y acontecimientos) y el acceso pleno a las fuentes de información, sin lo cual se bloquearía la libertad de información.

Sin embargo, los comunicadores a menudo presentan hechos evaluados, por lo que la información se condiciona mutuamente con la opinión en una relación de hechos valorados, en cuyo caso hay que atender al elemento preponderante.

A su vez, el derecho a recibir información obliga a los Estados y sus órganos y organismos a no realizar actos y conductas u omisiones destinadas a evitar o limitar la libre recepción de la información de carácter público, de relevancia pública o destinada al público, como asimismo, el deber de promover las condiciones que posibiliten su pleno ejercicio, eliminando los obstáculos o trabas factuales, jurídicas o conductuales que afecten o entorpezcan a través de limitaciones, controles o formalidades despropocionadas o irrazonables a la recepción de la información. ${ }^{15}$

Tal derecho así delimitado tiene como fronteras o límites que posibilitan restricciones preventivas las contenidas en el párrafo $4^{\circ}$ del artículo 13 de la $\mathrm{CADH}$ que autoriza la censura previa únicamente con el objeto de regular el acceso a espectáculos públicos de menores con la finalidad de proteger la moral de la infancia y la adolescencia, como asimismo, las suspensiones o restricciones del ejercicio de la libertad de expresión durante la vigencia de un estado de excepción constitu-

${ }^{14}$ De Domingo, Tomás. (2002). ¿Conflicto entre derechos fundamentales? Ed. Centro de estudios Políticos y Constitucionales. Madrid, p. 374.

${ }^{15}$ Ver Caso Austria contra Suiza. Tribunal Europeo de Derechos Humanos, sentencia de mayo de 1990. 
cional compatible con las exigencias del artículo 27 de la CADH y el artículo $4^{\circ}$ del P.I.D.C. y P. de Naciones Unidas.

La libertad de opinión e información asegurada por la Constitución y la libertad de expresión asegurada por la Convención Americana de Derechos Humanos en su Artículo 13 y el Pacto Internacional de Derechos Civiles y Políticos de Naciones Unidas en su artículo 19, armonizadas debidamente, permiten afirmar que toda persona tiene derecho no sólo a expresar sus ideas y juicios, sino que también tiene la libertad para buscar, investigar, transmitir o comunicar, emitir, publicar o difundir, y recibir ideas e informaciones de todo tipo.

El derecho a emitir juicios e ideas, y a trasmitir dichas opiniones y datos o acontecimientos de relevancia pública a terceros, comprende el derecho a utilizar cualquier forma de expresión (oral, escrita, artística, etc.) y cualquier medio adecuado para difundir las opiniones o informaciones (libros, prensa, radio, cine, tv, internet, satélite, cable, e-mail, etc.). El derecho a expresarse y a difundir lo expresado están intrínsecamente unidos, de manera que toda limitación o restricción a las posibilidades de trasmitir a terceros opiniones o informaciones, constituye una afectación del derecho a la libertad de expresión.

Sobre la dimensión individual del derecho a la libertad de expresión la Corte Interamericana ha determinado que ella "no se agota con el reconocimiento teórico del derecho a hablar o a escribir, sino que comprende además, inseparablemente, el derecho a utilizar cualquier medio apropiado para difundir el pensamiento y hacerlo llegar al mayor número de destinatarios. En este sentido, la expresión y difusión del pensamiento y de la información son indivisibles, de modo que una restricción de las posibilidades de divulgación representa directamente, y en la misma medida, un límite al derecho de expresarse libremente". ${ }^{16}$

La libertad de opinión y de información está al margen de toda censura previa, lo que preserva a las opiniones e informaciones del previo control de la autoridad sobre lo que se va a decir o a comunicar.

La censura está constituida por el control, el examen o permiso a que se somete cualquier texto o expresión artística con anterioridad a su comunicación al público, la censura tiene un carácter preventivo y su objeto es acallar las críticas a las diversas manifestaciones del poder temporal o religioso, realizada por cualquier órgano del Estado. ${ }^{17}$

\footnotetext{
${ }^{16}$ Sentencia de la Corte Interamericana de Derechos Humanos. "La última tentación de Cristo", de fecha 5 de febrero de 2001, Serie C No 73, párrafo 65.

${ }^{17}$ Ver Ekmekdjian, Miguel Ángel. Derecho a la información. Ed. Depalma, Segunda edición, Buenos Aires, Argentina. 1996, p. 38.
} 
Pierini, Lorences y Tornabene precisan que "censura es la decisión destinada a impedir la publicación o difusión de una actividad política, artística o periodística"18. Barrancos y Vedia, citados por Ekmekdjian, determinan que censura es toda amenaza, advertencia u otra forma, que "los órganos de cualquiera de los tres poderes del Estado dirijan a los medios de prensa, cuando tengan carácter intimidatorio". ${ }^{19}$

A su vez, Néstor Pedro Sagüés determina como censura previa "cualquier acto u omisión que inhabilite la publicación de algo (no provisión de papel, intervención arbitraria de una empresa periodística) o que tienda a influir en esa publicación o que dificulte que el producto informativo llegue normalmente a la sociedad" ${ }^{20}$

En la misma perspectiva, Nespal precisa que censura previa es "cualquier medida que impida, limite o dificulte que la información o la expresión de ideas llegue a la opinión pública. Puede afectar no sólo al periodismo sino también a toda persona que desee expresarse, la prohibición de censura previa es absoluta". ${ }^{21}$

La ausencia de censura previa implica falta de control de la autoridad en forma preventiva, no sólo la ausencia de control gubernamental, sino también de control administrativo y jurisdiccional. La responsabilidad por las opiniones emitidas o la relación de los hechos o juicios emitidos a través de un medio de comunicación social no puede ser preventiva lo que no implica que no exista responsabilidad o acciones posteriores a la publicación o difusión de las opiniones o informaciones, las que pueden ser civiles o penales, además del ejercicio del derecho de declaración, respuesta o rectificación.

En el ámbito nacional, el supremo interprete de la Constitución en el ámbito jurisdiccional, el Tribunal Constitucional, en posición divergente de la jurisprudencia de los tribunales ordinarios, en su fallo Rol 226 de fecha 30 de octubre de 1995 recaído en proyecto de ley sobre libertad de opinión e información y ejercicio del periodismo, reafirma como contenido esencial y medular de la libertad de opinión e información que ella sea sin censura previa, en considerando noveno y décimo de su sentencia, los que se transcriben:

"9) Que ha sido invariablemente reconocido por la doctrina constitucional que el núcleo esencial del derecho consagrado en el artículo $19 N^{\circ} 12$, sobre la libertad de opinar $y$ de informar reside en que estas libertades se pueden ejercer sin censura previa".

\footnotetext{
${ }^{18}$ Pierini, Lorences y Tornabene. Habeas Data, derecho a la intimidad, derecho a informar. Editorial Universidad de Buenos Aires, Argentina. 1999. p. 196.

${ }^{19}$ Ver EkmeKdjian, Miguel Ángel. (1996), p. 45

${ }^{20}$ SaGứés, Néstor Pedro. Elementos de Derecho Constitucional. Ed Astrea, Buenos Aires, 1997. Tomo 2, pág. 356.

${ }^{21}$ NeSpal, Bernardo. Derecho a la información. Ed B. De F., Montevideo, Uruguay. 1999. p. 230.
} 
"10) Que este sistema, que consiste en que el contenido esencial y medular de la libertad de opinión y de informar es que se puede informar sin censura previa, ha sido reconocido, por los demás, en los diversos textos constitucionales chilenos de manera tal que la esencia del derecho que nos preocupa está en que éste se ejerza libremente y que no exista censura previa que lo afecte".

Agregando con nitidez el Tribunal Constitucional que:

"Se afecta el contenido esencial de la libertad de emitir opinión y de informar sin censura previa, en cualquier forma y por cualquier medio ..... cuando ello significa "imponer condiciones que impiden su libre ejercicio; y es que se afecta su esencia desde el mismo instante que su ejercicio deja de ser libre" (considerando 31).

"... Tan sensible es esta libertad, que su reconocimiento desde antiguo en nuestro régimen republicano se ha expresado con fórmula lápidaria: "sin censura previa", término cuyo quid conceptual hoy no es otro que "sin interferencias de nadie" (considerando 31).

Es evidente que la libertad de opinión y de información protege la libre circulación de las ideas, lo que desarrolla un bien esencial de la vida democrática, por lo tanto, las injerencias en tal derecho sólo pueden concretarse a través de los órganos colegisladores para establecer una razonable, legítima y proporcionada regulación legislativa en salvaguardia de bienes jurídico constitucionales o de otros derechos fundamentales.

La Corte Interamericana de Derechos Humanos nos ha precisado que:

"116. La libertad de expresión, particularmente en asuntos de interés público, "es una piedra angular en la existencia misma de una sociedad democrática". No sólo debe garantizarse en lo que respecta a la difusión de información o ideas que son recibidas favorablemente o consideradas como inofensivas o indiferentes, sino también en lo que toca a las que resultan ingratas para el Estado o cualquier sector de la población. Tales son las demandas del pluralismo, que implica tolerancia y espiritu de apertura, sin los cuales no existe una sociedad democrática. Cualquier condición, restricción o sanción en esta materia deben ser proporcionadas al fin legitimo que se persigue. Sin una efectiva garantía de la libertad de expresión, se debilita el sistema democrático y sufren quebranto el pluralismo y la tolerancia; los mecanismos de control y denuncia ciudadana pueden volverse inoperantes y, en definitiva, se crea un campo fértil para que arraiguen sistemas autoritarios". 22

La libertad de opinión al constituir expresión de valores, creencias y emisión de juicios subjetivos, sin pretensión de afirmar datos objetivos o establecer hechos, dispone de un campo de acción mucho más amplio que la libertad de información,

\footnotetext{
${ }^{22}$ Corte IDH. Caso Perozo y otros Vs. Venezuela. Excepciones Preliminares, Fondo, Reparaciones y Costas. Sentencia de 28 de enero de 2009. Serie C No. 195, párrafo 116.
} 
ya que en este ámbito no opera la veracidad como límite o frontera del derecho, como tampoco constituye un límite que las opiniones sean de interés o relevancia pública, la cual tiene importancia sólo para resolver algunas tensiones frente a otros derechos.

Como señala la Corte Interamericana de Derechos Humanos, el Estado dentro del marco de garantizar los derechos, debe abstenerse de obstaculizar la libertad de expresión, como asimismo realizar acciones que la propicien y favorezcan, en otras palabras que la promuevan:

"118. El ejercicio efectivo de la libertad de expresión implica la existencia de condiciones y prácticas sociales que lo favorezcan. Es posible que esa libertad se vea ilegitimamente restringida por actos normativos o administrativos del Estado o por condiciones de facto que coloquen, directa o indirectamente, en situación de riesgo o mayor vulnerabilidad a quienes la ejerzan o intenten ejercerla, por actos u omisiones de agentes estatales o de particulares. En el marco de sus obligaciones de garantía de los derechos reconocidos en la Convención, el Estado debe abstenerse de actuar de manera tal que propicie, estimule, favorezca o profundice esa vulnerabilidad y ha de adoptar, cuando sea pertinente, medidas necesarias y razonables para prevenir o proteger los derechos de quienes se encuentren en tal situación, así como, en su caso, investigar hechos que los perjudiquen". 23

La Corte Interamericana de Derechos Humanos ha precisado que el Estado en su obligación de garante de los derechos puede ser responsable no sólo de los actos de sus propios agentes, sino también de la actuación de particulares, en casos específicos:

"120. La Corte ha señalado que la responsabilidad internacional del Estado puede generarse por actos violatorios cometidos por terceros, que en principio no le serían atribuibles. Esto ocurre si el Estado incumple, por acción u omisión de sus agentes que se encuentren en posición de garantes de derechos humanos, las obligaciones erga omnes contenidas en los artículos 1.1 y 2 de la Convención.

"121. La Corte también ha señalado que un Estado no es responsable por cualquier violación de derechos humanos cometida por particulares. El carácter erga omnes de las obligaciones convencionales de garantía no implica una responsabilidad ilimitada de los Estados frente a cualquier acto de particulares. Debe atenderse a las circunstancias particulares del caso y a la concreción de dichas obligaciones de garantía, considerando la previsibilidad de un riesgo real e inmediato". ${ }^{24}$

${ }^{23}$ Corte IDH. Caso Perozo y otros Vs. Venezuela. Excepciones Preliminares, Fondo, Reparaciones y Costas. Sentencia de 28 de enero de 2009. Serie C No 195, párrafo 118.

${ }^{24}$ Corte IDH. Caso Perozo y otros Vs. Venezuela. Excepciones Preliminares, Fondo, Reparaciones y Costas. Sentencia de 28 de enero de 2009. Serie C No 195, párrafos 120 - 121. 
La Corte Interamericana de Derechos Humanos nos recuerda que todo derecho tiene límites y no es absoluto, por lo cual puede ser restringido:

"117. Con todo, la libertad de expresión no es un derecho absoluto y puede estar sujeta a restricciones, en particular cuando interfiere con otros derechos garantizados por la Convención. Dada la importancia de la libertad de expresión en una sociedad democrática y la responsabilidad que entraña para los medios de comunicación social y para quienes ejercen profesionalmente estas labores, el Estado debe minimizar las restricciones a la información y equilibrar, en la mayor medida posible, la participación de las distintas corrientes en el debate público, impulsando el pluralismo informativo. En estos términos se puede explicar la protección de los derechos humanos de quien enfrenta el poder de los medios, los que deben ejercer con responsabilidad la función social que desarrollan, y el esfuerzo por asegurar condiciones estructurales que permitan la expresión equitativa de las ideas". ${ }^{25}$

Los insultos emitidos fuera del discurso y desconectados con el objeto de opinión se encuentran siempre fuera de la protección de la libertad de opinión.

Asimismo, las alusiones ofensivas a grupos ya sea por razones de raza, sexo u otros ámbitos similares tampoco se encuentran protegidos por la libertad de opinión, en la medida que ellos no contribuyen al desarrollo libre de las ideas, ni contribuyen a la formación de una opinión pública, no siendo necesarias para la transmisión de ideas, además de ser expresiones odiosas, que afectan el derecho a la igualdad y contrarias al respeto de la dignidad de las personas que forman parte de dicho grupo humano.

Es interesante en la materia considerar otra sentencia del Tribunal Constitucional español. En este caso, un señor León Degrelle, ex miembro de la S.S. nazi había expresado en la Revista Tiempo, refiriéndose a los judíos bajo el régimen nazi, que las matanzas de judíos en los campos de exterminio nazis nunca habían ocurrido, lo que no era más que una invención de los judíos, quienes buscaban aparecer como víctimas ante la comunidad. Frente a tales opiniones, la señora Violeta Friedman, judía que había estado internada en el campo de Auschwitz donde murió la mayoría de su familia en una cámara de gas, interpuso una demanda contra Degüelle, por violación de su derecho al honor. Los tribunales ordinarios de primera instancia, apelación y el Tribunal Supremo en casación, desestimaron la demanda por falta de legitimación activa, por lo cual la demandante recurrió de amparo ante el Tribunal Constitucional, el cual resolvió a su favor, declarando la nulidad de las resoluciones de los tribunales ordinarios, en el fallo, el cual sostuvo:

\footnotetext{
${ }^{25}$ Corte IDH. Caso Perozo y otros Vs. Venezuela. Excepciones Preliminares, Fondo, Reparaciones y Costas. Sentencia de 28 de enero de 2009. Serie C No. 195, párrafo 117.
} 
"[...] También es posible apreciar lesión del citado derecho fundamental en aquellos supuestos en los que, aun tratándose de ataques referidos a un determinado colectivo de personas, más o menos amplio, los mismos trascienden a sus miembros o componentes, siempre y cuando éstos sean identificables, como individuos dentro de la colectividad. Dicho en otros términos, el significado personalista que el derecho al honor tiene en la Constitución no impone que los ataques o lesiones al citado derecho fundamental, para que tengan protección constitucional, hayan de estar necesariamente perfecta y debidamente individualizados ad personam, pues, de ser asi, ello supondría tanto como excluir radicalmente la protección del honor de la totalidad de las personas jurídicas, incluidas las de substrato personalista, y admitir, en todos los supuestos, la legitimidad constitucional de los ataques o intromisiones en el honor de las personas, individualmente consideradas, por el mero hecho de que los mismos se realicen de forma innominada, genérica o imprecisa" (26).

El Tribunal Constitucional, una vez reconocida la legitimación activa de la señora Friedman, determinó que las opiniones del demandado en torno a los acontecimientos históricos y otras interpretaciones de dichos eventos, aun cuando reprobables, se encontraban protegidos por el derecho a la libertad de expresión, pero no se encontraban protegidas las expresiones ofensivas en contra del pueblo judío, ya que las campañas de carácter racistas no se encuentran protegidas por la libertad de expresión, el fundamento de tal exclusión radica en la protección de otros bienes y derechos constitucionales tales como la dignidad humana, la igualdad y el honor. Al respecto el Tribunal Constitucional sostuvo:

"Ni la libertad ideológica (art. 16 CE) ni la libertad de expresión (art. 20.1 CE) comprenden el derecho a efectuar manifestaciones, expresiones o campañas de carácter racista o xenófobo, puesto que, tal como lo dispone el art. 20.4, no existen derechos ilimitados y ello es contrario, no sólo al derecho al honor de la persona o personas directamente afectadas, sino a otros bienes constitucionales como el de la dignidad humana [...]. La dignidad como rango o categoría de la persona como tal, del que deriva y en el que se proyecta el derecho al honor (art. $18 \mathrm{CE}$ ), no admite discriminación alguna por razón de nacimiento, raza, sexo, opiniones o creencias. El odio y el desprecio a todo un pueblo o a una etnia (a cualquier pueblo o a cualquier etnia) son incompatibles con el respeto a la dignidad humana que sólo se cumple si se atribuye por igual a todo hombre, a toda etnia, en cuanto protege y expresa el sentimiento de la propia dignidad resulta, sin duda, lesionado cuando se ofende y desprecia genéricamente a todo un pueblo o raza, cualesquiera que sean. Por ello, las expresiones y aseveraciones

\footnotetext{
${ }^{26}$ Sentencia del Tribunal Constitucional español, 214/1991, del 11 de noviembre de 1991, fundamento sexto.
} 
proferidas por el demandado también desconocen la efectiva vigencia de los valores superiores del ordenamiento, en concreto al valor de igualdad consagrado en el art. 1.1. de la Constitución, en relación con el art. 14 de la misma, por lo que no pueden considerarse como constitucionalmente legitimas" $\left.{ }^{27}\right)$.

En el ámbito americano y específicamente chileno, los bienes jurídicos constitucionales que habilitan para justificar limitaciones a la libertad de expresión están dados por la dignidad humana (art. 10), la igualdad (art. 19 No 2) y la honra de la persona y su familia (art. 19 No 4). Además, la norma sancionatoria de dichas conductas podría reforzarse con el art. 13, numeral 5 de la Convención Americana de Derechos Humanos, el cual determina:

"Estará prohibido por la ley toda propaganda y toda apología del odio nacional, racial o religioso que constituyan incitaciones a la violencia o cualquier otra acción ilegal similar contra cualquier persona o grupo de personas, por ningún motivo, inclusive los de raza, color, religión, idioma u origen nacional".

\section{CONCLUSIÓN}

En tal sentido podemos informar a vuestra comisión que una norma penal sancionatoria de conductas antijurídicas, típicas y culpables o dolosas, como la que se expresa en el artículo único del proyecto tiene plena justificación en virtud de bienes jurídicos constitucionales que posibilitan en este caso, la restricción de la libertad de expresión u opinión.

Sin embargo, debe dicha disposición legal cumplir con los requisitos de clara determinación y especificidad del tipo penal, no estableciendo normas abiertas que afecten la seguridad jurídica de las personas, debiendo la norma que se apruebe determinar específica y completamente la conducta punible o reprochable, la que debe ser previsible para cualquier persona.

El Tribunal Constitucional precisa que las limitaciones o restricciones a los derechos fundamentales pueden establecerse:

"únicamente en los casos o circunstancias que en forma precisa y restrictiva indica la Carta Fundamental; y que, además, tales limitaciones deben ser señaladas con absoluta precisión, a fin de que no sea factible una incorrecta o contradictoria interpretación. Asimismo, esa exigida precisión debe permitir la aplicación de las restricciones impuestas de una manera igual para todos los afectados, con parámetros incuestionables..." (STC, Rol 226, considerando 47).

En tal sentido, nos parece necesario afinar el texto propuesto determinando específicamente los tipos penales, para lo cual debe distinguirse los crímenes de

${ }^{27}$ Sentencia del Tribunal Constitucional español 214/1991, fundamento octavo. 
lesa humanidad, crímenes de guerra, el genocidio o cualquier otro tipo penal que se considere pertinente, ya sea por vinculación con las disposiciones pertinentes del Código Penal o en relación a la normativa contenida en el Tratado de Roma sobre Tribunal Penal Internacional que el Estado de Chile ha ratificado y que se encuentra vigente.

Finalmente, en derecho no se utiliza el concepto de "cárcel" para la consideración de la pena sino los conceptos de "presidio" o "reclusión", la fijación de las penas se realiza con guarismos del nivel más bajo al más alto, debiendo determinarse el tipo de pena temporal -mayores o menores- y los grados respectivos y accesorias correspondientes.

Es todo cuanto podemos informar a vuestra comisión.

Participaron en la confección de este informe los profesores doctores Liliana Galdamez Zelada, Domingo Hernández Emparanza y Humberto Nogueira Alcalá.

En Santiago de Chile, a 17 de abril de 2012.

Humberto Nogueira Alcalá

Director Ejecutivo Centro de Estudios Constitucionales de Chile

Universidad de Talca, Campus Santiago 
